\title{
A review of multi-criteria decision making techniques for supplier evaluation and selection
}

\author{
Prince Agarwal, Manjari Sahai, Vaibhav Mishra, Monark Bag* and Vrijendra Singh
}

Indian Institute of Information Technology Allahabad, U.P-211012, India

\begin{tabular}{l}
\hline A R T I C L E I N F O \\
\hline Article history: \\
Received 11 May 2010 \\
Received in revised form \\
June, 14, 2011 \\
Accepted 14 June 2011 \\
Available online \\
15 June 2011 \\
\hline Keywords: \\
Supplier selection \\
Supplier evaluation \\
MCDM \\
Supply chain management
\end{tabular}

Supply chain management

\begin{abstract}
A B S T R A C T
Supplier evaluation and selection has been a vital issue of strategic importance for long time. Different multi-criteria decision making (MCDM) approaches have been proposed by the researchers in past, to solve the supplier evaluation and selection problem. In this paper, we present a review of various MCDM methodologies reported in the literature for solving the supplier evaluation and selection process. The review is solely based on sixty-eight research articles, including eight review articles in the academic literature from 2000 to 2011 . We try to find out the most prevalent approach in the articles and thereby present the future scope of arriving at an optimal solution to the problem, based on the specifications, the strategies and the requirements of the buyers. The study presents that with the change in processes and the requirements, how the approach of the manufacturing industry has shifted from striving for operational effectiveness to the strategic partnership in the dyadic relationship.
\end{abstract}

(C) 2011 Growing Science Ltd. All rights reserved

\section{Introduction}

In every industry, the proper evaluation and selection of suppliers is very crucial for the progress and development. With the wide use of enterprise systems and emphasis on quality improvement concepts, the managers try to go beyond the conventional boundaries of money and material and try to explore the vast new universe of possibilities. In most of the business processes, it has become essential for the firms to go for few and trusted suppliers who can provide the high quality goods with minimum lead time and affordable prices. Supplier selection has turned to be an important constituent of the organization decision making and has proved to provide a competitive edge over the competitors, while maintaining the strategic and operational bindings. The concept of just-in-time (JIT) manufacturing has put additional pressure on the suppliers emphasizing on delivery performance, quality and strategic integration between the two firms. Supplier selection involves various criteria including speed, delivery performance, price, quality, reliability, etc and often involves the selection of one while sacrificing the other. Consider a situation in which one supplier is providing goods in cheap rates but is not able to deliver on time. On the other hand, another supplier is providing the best quality goods but the delivery performance and prices are not acceptable. Therefore, supplier selection belongs to the class of multi-criteria decision making (MCDM) problem in which the firms need to identify the top priorities of selecting the best supplier based on its working style and the industry type.

\footnotetext{
* Corresponding author. Tel.: +91-0532-2430006 (Extn-2174) (O) Fax No. : +91-0532-2430006/2431689

E-mail: monarkbag@gmail.com / monark@iiiita.ac.in (M. Bag)

(c) 2011 Growing Science Ltd. All rights reserved.

doi: $10.5267 /$ j.ijiec.2011.06.004
} 
Different researchers have proposed extensive MCDM techniques to provide a feasible and effective solution to supplier selection problem, which mainly includes simple technique of weighted sum model (WSM) to more complex ones like analytical hierarchy process (AHP), data envelopment analysis (DEA), analytic network process (ANP), ELECTRE (Elimination Et Choix Traduisant la REalite - ELimination and Choice Expressing the Reality), fuzzy approaches, PROMETHEE (Preference Ranking Organization Method for Enrichment Evaluation), artificial neural network (ANN) based approaches, simple multi-attribute rating technique (SMART), etc. This paper focuses on the various MCDM techniques proposed in the past and try to evaluate them to find out the most prominent technique. Different researchers have studied the literature survey in the past pertaining the supplier evaluation and selection problem (Weber et al., 1991; Degreave et al., 1991; Holt, 1998; Boer et al., 2000; Aamer \& Sawhney, 2004; Tahriri et al., 2008; Ho et al., 2010; Cheraghi et al., 2011). This paper extends the research by surveying different articles in different approaches of MCDM models, and thereby tries to find out which approach is the most prevalent and the approaches, which could prove to be more efficient.

\section{Various approaches}

The researchers have used various approaches to solve the complex and uncertain MCDM problems of supplier evaluation and selection. Most of them mainly include DEA, mathematical models, AHP, linear programming, ANP, SMART, etc.

\subsection{Data envelopment analysis (DEA)}

Data envelopment analysis (DEA) is an approach, which mainly focuses on the system efficiency. This approach, considers suppliers and their processes as a system, in which the output (benefit) is identified as the weighted sum of the outputs (e.g. delivery performance, quality, etc.) of the suppliers and the inputs are the weighted sum of inputs (costs). Using the outputs and inputs, the efficiency of the system is determined. Using DEA, the researchers have proposed how to find out the optimal weights to maximize the supplier's performance ratings (efficiency). The method is then used to classify the suppliers as efficient and inefficient.

Efficiency $=\frac{\text { Weighted sum of Output }}{\text { Weighted sum of Inputs }}$

Weber (1996) applied DEA for a single product and proposed a model from the organizations to use it for supplier selection for other products as well. In his model, six vendors were evaluated who were supplying some product to baby food manufacturing company. He showed how much reductions in cost and improvement in quality could be achieved while maintaining the delivery performance. Braglia and Petroni (2000) conducted a questionnaire survey with 89 manufacturing firms in Brescia (Europe) and applied DEA to measure the related performance of various suppliers based upon the article of Baker and Talluri (1997). They proposed nine evaluating factors to evaluate the suppliers. Liu et al. (2000) came up with the simplified DEA model to evaluate the supplier performance with 3 inputs, price index, delivery performance and distance factor, and 2 output criteria which are supply variety and quality. Forker and Mendez (2001) proposed the application of DEA to measure comparative efficiency of suppliers. Comparative efficiency was calculated as a ratio of single input to multiple outputs. Similar to Braglia and Petroni (2000), this article also focused on evaluating the related performance of various suppliers based on the cross efficiencies. Specific to a multi-national corporation in the telecommunication industry, Narasimhan et al. (2001) came up with proposed evaluating factors to apply DEA for supplier evaluation. Out of the eleven factors considered, there were six inputs, which denoted supplier's capability and five outputs, which symbolized supplier's performance. They classified suppliers into four sections based on performance and efficiency. As shown in Fig. 1, the researchers classified the suppliers into four quadrants to eliminate the less desired ones. 
Efficiency

\begin{tabular}{|l|l|l|}
\cline { 2 - 4 } Performance & High performance and high efficiency & High performance and low efficiency \\
\cline { 2 - 4 } & Low performance and high efficiency & Low performance and low efficiency \\
\hline
\end{tabular}

Fig. 1. Classification based on performance and efficiency

Talluri and Baker (2002) used two input factors and four output factors to evaluate potential stakeholders, which are suppliers, manufacturers, distributors, retailers. They used three-phase approach for logistic distribution network design. The optimal supplier was selected for different locations and products as per the requirements. Using the same evaluating factors proposed by Talluri and Sarkis (2002), Talluri and Baker (2002) they measured supplier performance by applying DEA and showed that the model works. Talluri and Narasimhan (2004) proposed DEA for effective sourcing purpose. The model used cross-efficiencies and statistical methods in clustering the supply base. Garfamy(2006) applied DEA to minimize total cost of ownership (TCO) and proposed the application of DEA in evaluating the supplier performance based on TCO; and tried to simulate data of a hypothetical firm with the strategic aim of being able to reduce TCO with identification of benchmarks. Ross et al. (2006) identified the DEA methodology as the basis for an iterative analytical and broader framework - namely action research (AR). The proposed methodology fused both buyer and supplier performance attributes and was found capable of delivering measurable and actionable outputs.

There were two main goals: first, to set up a mutual and reciprocal understanding of the opposite needs of the buyers and suppliers in the relationship dyad and, second, to discuss an approach, which could help evaluate performance in the relationship. Saen (2006) developed a model based on DEA to evaluate technology suppliers on mainly three factors. The idea was to propose a DEA based method for selecting technology suppliers, knowing in advance the nondiscretionary factors from supplier's perspective and the qualitative factor, which ranked them on the scale of five. Seydel (2006) used DEA to solve supplier selection issue. The important thing in this article was that unlike the other approaches, no input was considered in this model. The article used seven point scales to rank the qualitative aspects of the suppliers. Further the article points that the proposed DEA required less effort than simple multi-attribute rating technique (SMART). Talluri et al. (2006) proposed a chanceconstrained DEA approach to evaluate supplier performance taking into consideration the stochastic performance measures. This study proposed that in order to predict the supplier performance, understanding the variability in vendor attributes is important. The input criteria considered was price, while the outputs were delivery and quality. The comparison of the model with the deterministic DEA highlighted its usefulness.

$\mathrm{Wu}$ et al. (2007) proposed an augmented DEA approach for selection of suppliers. The model was capable to handle imprecise data to rank the efficient suppliers and covered the discrimination among them based on discriminating efficient suppliers from relatively poor performers. The researchers designed a web-based system to allow interested parties in supplier evaluation and selection. Kao (2010) proposed common weight DEA for ranking alternatives and focused on measuring the relative distance of the alternative from the ideal or best alternative as per the criteria and anti-ideal alternative or worst alternative. If in case two options have the same distance from the ideal alternative, then the one with higher distance from the anti-ideal would be selected as the better option of the two and hence ranked higher. Mondal and Chakraborty (2010) proposed the idea of selecting the flexible manufacturing system in an organization using DEA. Initially, the alternatives were shortlisted on the basis of the best criterion as per Charnes, Cooper and Rhodes (CCR) DEA model and then the shortlisted alternatives are ranked based on the weighted efficiency ranking method of MCDM theory. Songhori et al. (2011) presented a structured framework to help decision makers in selecting the best supplier for their firm using DEA. The proposed model had two separate but dependent phases, which are the selection phase and the allocation phase. 


\subsection{Mathematical Programming Models}

\subsubsection{Linear Programming}

Talluri and Narasimhan (2003) are the first group of researchers who focused on the importance and implications of performance variability in evaluating different suppliers. The researchers saw the process as a system in which the main objective was to minimize the input items such as cost and to maximize the outputs such as quality, delivery performance, etc. The researchers proposed two linear programming (LP) models so that groups of homogenous suppliers can be easily identified, which provides discriminate choices in final selection. Talluri and Narasimhan (2005) designed a linear programming model to help decision makers or buyers select and evaluate different suppliers. The model is based on quantitative measures to select potential suppliers considering the strengths of existing suppliers and to eliminate underperforming suppliers, taking the case of a large, multinational, telecommunications company. The researchers further compared the effectiveness of the proposed model with traditional and advanced DEA, to determine its advantages. $\mathrm{Ng}$ (2008) developed a weighted linear programming (WLP) model for supplier selection, using the subjective and mathematical approach to maximize the supplier score. The researcher proposed a transformation technique, which eliminates the need of optimization to solve the weighted linear program.

\subsubsection{Integer linear programming}

Talluri (2002) proposed a binary integer linear programming model for evaluating alternative supplier bids. The researcher proposed the use of alternative bid ratings in selecting an optimal set of bids, which satisfy the demand requirements. Talluri (2002) proposed four variations of the model to assist the buyer in making effective decisions in different environments. Hong et al. (2005) developed a model based on mixed-integer linear programming (MILP) for the supplier selection, which not only maximizes revenue but also helps fulfilling customer's needs. The main objective was to find out optimal number of suppliers and order quantity in order to maximize revenue with consideration of

variability in the customer needs and suppliers performance. Rajan et al. (2010) proposed supplier selection model for multiproduct, multi-vendor environment based on integer linear programming (ILP) model. The proposed model was validated on agriculture equipment wholesaler.

\subsubsection{Integer non-linear programming}

Ghodsypour and O'Brien (2001) used the concept of mixed integer non-linear programming to propose a model to solve the supplier selection problem. The researchers' model was designed to find the optimum number of suppliers and order size to be allocated to each supplier, in order to minimize the overall annual purchasing cost. The article was divided into two groups: single and multi objective.

\subsubsection{Goal programming}

Karpak et al. (2001) are the first group of researchers who proposed goal programming (GP) model to evaluate the suppliers. Quality, cost, and delivery performance were the three identified objectives. The model was to find out the optimal quantity of products (ordered), subject to demand and supply constraints.

\subsubsection{Multi-objective programming}

Narasimhan et al. (2006) developed a multi-objective programming model to solve supplier selection problem and came out with the optimal order quantity. Five criteria, minimum order size, maximum available supply, stipulate price, quality, and promised delivery-performance levels, were used to evaluate the suppliers' performance. Wadhwa and Ravindran (2007) proposed another multiobjective programming model to solve the supplier evaluation and selection problem, wherein there were three minimization functions: price, lead time, and rejections. To solve the resulted mentioned 
cases, three solution approaches, weighted objective, goal programming and compromise programming method, were used to discriminate and compare the solutions.

\subsection{Analytic hierarchy process (AHP)}

Akarte et al. (2001) identified eighteen criteria, six objective types and twelve subjective, for supplier assessment and divided them into four groups: quality capability, product development capability, manufacturing capability, and cost and delivery. The researchers developed a web-based system to evaluate the suppliers. Muralidharan et al. (2002) developed a five-step AHP-based model, which incorporated nine evaluating criteria for rating and selecting suppliers. People from different departments, such as quality control, purchasing, and stores, were concerned in the selection process. Chan (2003) developed selection model using AHP, which facilitated selection of suppliers. Chan and Chan (2004) used AHP hierarchy to evaluate and select suppliers. Their model consisted of six evaluating criteria and 20 sub-factors. Computations of different relative importance ratings were performed based on the customer requirements. Liu and Hai (2005) used similar approach proposed by Chan and Chan (2004) with a difference that they used Noguchi's voting and ranking method. This method helped manager in voting and in determining the criteria order instead of the weights. Chan et al. (2007) proposed an AHP-based multi-criterion decision making approach of supplier selection and their evaluation was performed based on 14 different criteria. They proposed a model to provide a framework to select appropriate suppliers and provided some details on how to deploy organization's strategy for the suppliers. Hou and $\mathrm{Su}$ (2007) developed a distributed system to identify appropriate suppliers for components in a mass customization environment. Their method uses dynamic and robust method of evaluating product market position and development directions.

Chan and Chan (2010) proposed an AHP based model to solve the supplier evaluation and selection problem taking the example of fashion industry. The article was mainly pivoted around the quick response (responsive) strategy, largely followed by apparel industry. The researchers divided the criteria into two major groups of performance criteria and company strategy based criteria. A total of twenty nine criteria were identified out of which nineteen belonged to performance group and the rest belonged to company strategy based criteria group, to have a strategic fit with the supplier. Kumar and Roy (2011) proposed a rule based model with the application of AHP to aid the decision makers in vendor evaluation and selection taking the power transmission industry. The article presented a three-step model to calculate the performance scores of various vendors and select the best vendor. The researchers also validated the proposed model taking the data from a multinational transformer company.

\subsection{Case based reasoning (CBR)}

Choy and Lee (2002) proposed a generic model of CBR integrating customer relationship management (CRM) and supply chain management (SCM) to identify appropriate supplier for the products, services and distribution. Different evaluating criteria were categorized as: quality system, technical capability, and organizational profile. The model was executed for a consumer products manufacturing company, which maintained a database of past suppliers and their attributes. The selection of supplier was performed by fulfillment of the defined specification. Choy et al. (2002), Choy and Lee (2003), Choy et al. (2003a), Choy et al. (2003b), Choy et al. (2004), Choy et al. (2005) applied the CBR based methodology for supplier selection problem. This approach was similar to the one proposed by Choy and Lee (2002), including the framework for supplier selection. In addition, testing on the data was performed for the same company based on the proposed model.

\subsection{Analytic network process (ANP)}

Sarkis and Talluri (2002) introduced a dynamic strategic decision model based on ANP (Saaty, 1996) to help decision makers select best supplier for their firm, taking inputs from all managerial levels, from strategic to operational, in the dynamic ever changing environment. The authors identified and applied seven evaluating criteria to evaluate the suppliers. Bayazit (2006) proposed an ANP based 
methodology, which incorporates feedback and interdependent relationships in evaluating and selecting best supplier for a firm. The researcher identified ten evaluating criteria in the model, classified into supplier's performance and capability clusters. A pair wise comparison matrix was setup to formulate interrelationships among all criteria. Gencer and Gürpinar (2007) proposed an ANP based model for an electronic company for supplier evaluation and selection with respect to various evaluating criteria. The proposed model consisted of forty-five criteria classified under three main criteria cluster.

\subsection{Fuzzy set theory}

Chen et al. (2006) proposed a hierarchy based MCDM model to deal with supplier selection problem. The researchers proposed the linguistic values, expressed in trapezoidal or triangular fuzzy numbers used to analyze the weights and the rate of the evaluation factors. The proposed model was validated on a high technology manufacturing firm to select key suppliers for components of a new product. Sarkar and Mohapatra (2006) developed a systematic framework to reduce the number of suppliers in order to facilitate the decision makers in selecting the best supplier. They suggested that capability and performance were the major dimensions in supplier selection. The researchers presented the capability-performance matrix that help in arranging the suppliers in decreasing order of preference. In order to validate the framework, a hypothetical case was considered to show how two best suppliers were selected with four performance-based and ten capability-based factors.

Florez-Lopez (2007) presented an approach to obtain an index of supplier preference and considered fourteen evaluating factors out of eighty-four potential value added attributes. The considered factors were based on the survey of US purchasing managers. The researchers presented a two-tuple fuzzy linguistic model to combine both numerical and linguistic information. Büyüközkan and Çifçi (2011) proposed a novel framework based on fuzzy set theory for solving the multi-criteria decision-making problem under incomplete relations. The researchers proposed the framework for sustainable supplier selection based on some criteria such as time pressure, lack of expertise in the related area and focused on the skill set and capability of the supplier in delivering the products called robust system. Chang et al (2011) proposed fuzzy decision making trial and evaluation laboratory (DEMATEL) method to effectively find evaluation factors for supplier selection. This method is based on practical approach of finding key factors to improve supplier performance through different questionnaire. Jiang and Chan (2011) proposed a methodology with the application of fuzzy set theory (FST), based on twenty criteria to deal with supplier evaluation and selection problem. They used the Dempster Shafer theory (DST) to combine the criterion data to calculate the final scores of the suppliers.

\subsection{Simple multi-attribute rating technique (SMART)}

Barla (2003) proposed a five-stage multi attribute selection model (MSM) for vendor evaluation and selection taking the case of a glass manufacturing company. In the model, seven evaluating criteria of reliability, capability, quality organization, geographic location, financial condition, service level and price were considered. Huang and Keska (2007) presented an integration mechanism to form a comprehensive and configurable metrics arranged hierarchically, which considers product type, original equipment manufacturer (OEM)/supplier and the level of supplier integration. The model was to find the best strategic fit between the firms and the supplier's strategy based on the set of metrics. The model was so developed that the best possible decision could be made based on the chosen and validated set of metrics. The researchers presented a total of one hundred and one metrics for supplier selection.

\subsection{Genetic algorithm}

Ding et al. (2005) proposed a new simulation optimization methodology to facilitate buyers in evaluation and selection of suppliers. The researchers presented a Genetic Algorithm (GA) based optimization methodology. The proposed methodology comprised three basic modules: a discrete- 
event simulator, a GA optimizer, and supply chain modeling framework. The possible configurations of the suppliers were selected and then validated on the basis of the key performance indicators.

\subsection{Criteria based decision making methods}

Almeida (2007) proposed the application of ELECTRE (Elimination Et Choix Traduisant la REalite ELimination and Choice Expressing the Reality) method for solving the supplier selection problem. The article used ELECTRE for multi-criterion evaluation and used utility function to evaluate different alternatives. Athawale et al (2009) proposed the application of PROMETHEE, Preference Ranking Organization Method for Enrichment Evaluation, to facilitate the buyers in the process of supplier evaluation and selection. The scholars used the qualitative and quantitative criteria and their relative importance to rank various suppliers, helping in better evaluation and selection. The researchers verified the application of PROMETHEE taking the real life data of a company. Athawale et al (2010) proposed the application of PROMETHEE-II in solving the complex MCDM problem of supplier evaluation and selection. The researchers verified the application of PROMETHEE-II taking the real life data of two companies. Zolghadri et al (2011) presented the concept of power based evaluation and selection. According to the article, strong suppliers can exert more power to influence the product development process for their own benefits. The researchers considered the customer perspective in the dyadic relationship and proposed a method for estimating the relative powers of supplier and buyer.

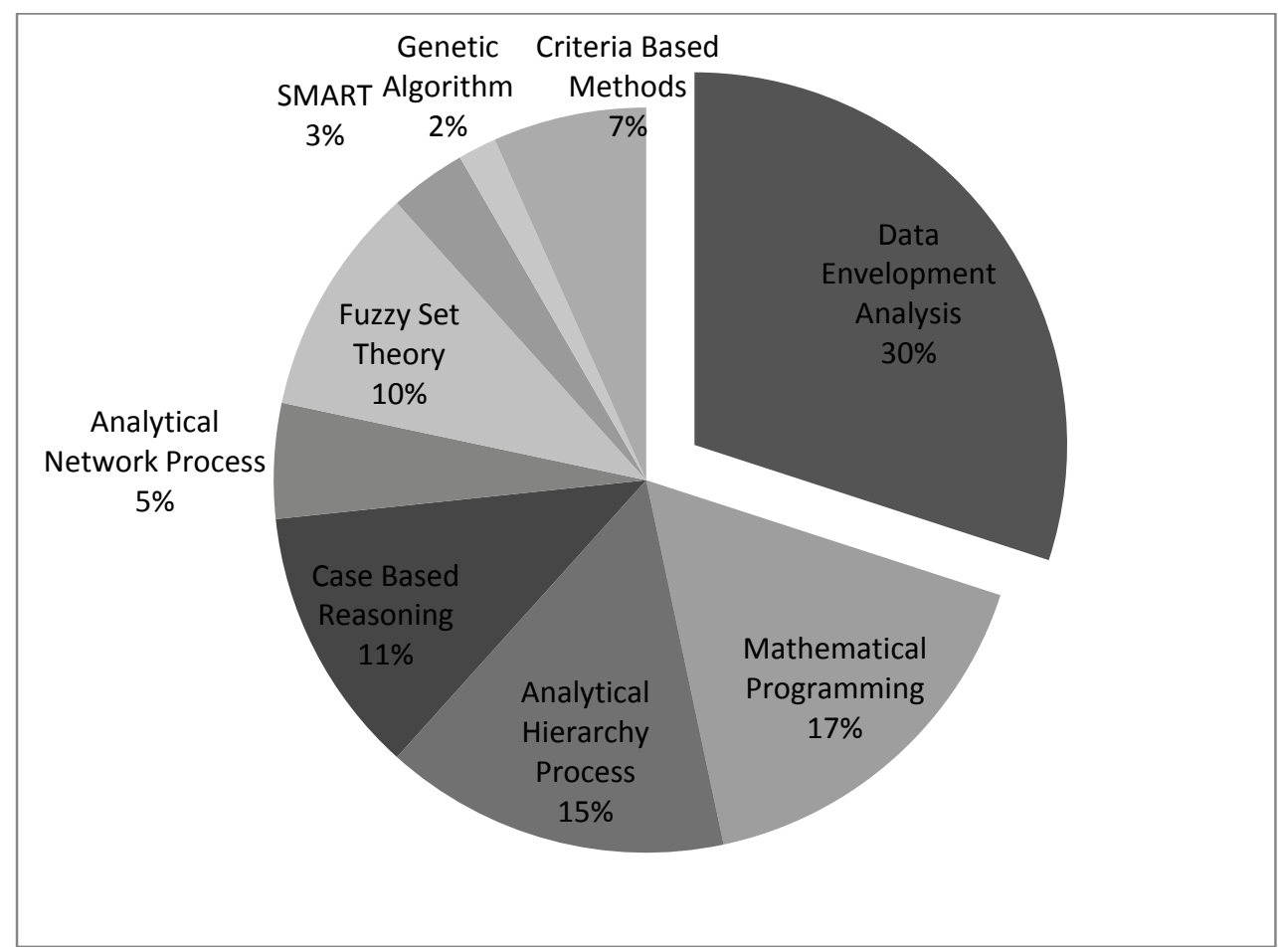

Fig. 2 The percentage distribution of the number of articles under various MCDM approaches

\section{Conclusions}

In this paper, sixty articles from various journals and conferences have been studied to find out the most prominent MCDM methodology followed by the researchers. The distribution of the articles under various classes of MCDM methods is shown in Fig. 2. The paper is intended to review different methodologies proposed by many researchers for supplier evaluation and selection from 2000 to 2011. First, different approaches followed by the researchers were studied and then the most prominent approach was identified. There were various approaches focused on qualitative and 
quantitative factors pertaining to the needs and specifications of the buyers. The most widely applied methodology was data envelopment analysis (DEA), mainly attributed for its robustness.

There is a need to evaluate the suppliers based on the inputs of the strategic, functional and operational levels. The implication of lean manufacturing and popularly used JIT approach has forced the researchers to shift the focus from the efficiency based model to quality based approach. The single criterion approach of the lowest cost supplier is no more accepted in this challenging and continuously changing environment. Thus, price or cost shifted down the line with respect to its importance in evaluating the suppliers, while the quality and delivery performance climbed up the hierarchy. Many evaluating criteria can be derived depending on the requirements of the company. Thus, it is important to analyze and prioritize different selection methods to satisfy stakeholders. Using methods like DEA, AHP, etc. suppliers can be ranked and evaluated to make an optimal supplier selection. Some methods can be beneficial to some specific companies so it is important to evaluate suppliers according to companies' specifications. In addition, AHP is used to evaluate supplier according to different categories to provide consistency in supplier selection. Thus, AHP can definitely aid the researchers and decision makers in meeting the challenging task of the supplier selection problem effectively in the near future.

\section{References}

Aamer A.M., \& Sawhney R. (2004). Review of Suppliers Selection from a Production Perspective. Proc. IIE Conference, 2135-2140.

Akarte, M.M., Surendra, N.V., Ravi, B., \& Rangaraj, N. (2001). Web based casting supplier evaluation using analytical hierarchy process. Journal of the Operational Research Society, 52 (5), 511-522.

Almeida A.T. (2007). Multicriteria decision model for outsourcing contracts selection based on utility function and ELECTRE method. Computers \& Operations Research, 34 (12), 3569 - 3574.

Athawale V.M., Chatterjee P., \& Chakraborty S. (2009). Supplier Selection using PROMETHEE method. Proc. International Conference on Advances in Mechanical Engineering, S.V. National Institute of Technology, Surat, 1009-1013.

Athawale V.M., Chatterjee P., \& Chakraborty S. (2010). Supplier Selection using PROMETHEE-II method. International Journal of Manufacturing Technology and Industrial Engineering, 1(1), 95-102.

Baker, R.C., \& Talluri, S. (1997). A closer look at the use of DEA for technology selection. Computers and Industrial Engineering, 32 (1), 101-108.

Bayazit, O. (2006). Use of analytic network process in vendor selection decisions. Benchmarking: An International Journal, 13 (5), 566-579.

Barla, S.B. (2003). A case study of supplier selection for lean supply by using a mathematical model. Logistics Information Management, 16 (6), 451-459.

Boer L., Labro E., \& Morlacchi P. (2000). A review of methods supporting supplier selection. European Journal of Purchasing \& Supply Management, 7 (2), 75-89.

Braglia, M., \& Petroni, A. (2000). A quality assurance-oriented methodology for handling trade-offs in supplier selection. International Journal of Physical Distribution and Logistics Management, 30 (2), 96-111.

Büyüközkan G., \& Çifçi G. (2011). A novel fuzzy multi-criteria decision frame work for sustainable supplier selection with incomplete information. Computers in Industry, 62 (2), 164-174.

Chan F.T.S., \& Chan H.K. (2010). An AHP model for selection of suppliers in the fast changing fashion market. International Journal of Advanced Manufacturing Technology, 51, 1195-1207.

Chan, F.T.S. (2003). Interactive selection model for supplier selection process: An analytical hierarchy process approach. International Journal Production Research, 41 (15), 3549-3579.

Chan, F.T.S., \& Chan, H.K. (2004). Development of the supplier selection model - A case study in the advanced technology industry. Proceedings of the Institution of Mechanical Engineers Part B - Journal of Engineering Manufacture, 218 (12), 1807-1824.

Chan, F.T.S., Chan, H.K., Ip, R.W.L., \& Lau, H.C.W. (2007). A decision support system for supplier selection in the airline industry. Proceedings of the Institution of Mechanical Engineers Part B - Journal of Engineering Manufacture, 221 (4), 741-758.

Chang B., Chang C., \& Wu C. (2011). Fuzzy DEMATEL method for developing supplier selection criteria. Expert Systems with Applications, 38, 1850-1858. 
Chen, C.T., Lin, C.T., \& Huang, S.F. (2006). A fuzzy approach for supplier evaluation and selection in supply chain management. International Journal of Production Economics, 102 (2), 289-301.

Choy, K.L., \& Lee, W.B. (2002). A generic tool for the selection and management of supplier relationships in an outsourced manufacturing environment: The application of case based reasoning. Logistics Information Management, 15 (4), 235-253.

Choy, K.L., Lee, W.B., \& Lo, V. (2002). Development of a case based intelligent customer - Supplier relationship management system. Expert Systems with Applications, 23 (3), 281-297.

Choy, K.L., \& Lee, W.B. (2003). A generic supplier management tool for outsourcing manufacturing. Supply Chain Management: An International Journal, 8 (2), 140-154.

Choy, K.L., Fan, K.K.H., \& Lo, V. (2003a). Development of an intelligent customer- supplier relationship management system: The application of case-based reasoning. Industrial Management and Data Systems, 103 (4), 263-274.

Choy, K.L., Lee, W.B., \& Lo, V. (2003b). Design of a case based intelligent supplier relationship management system - The integration of supplier rating system and product coding system. Expert Systems with Applications, 25 (1), 87-100.

Choy, K.L., Lee, W.B., \& Lo, V. (2004). An enterprise collaborative management system - A case study of supplier relationship management. The Journal of Enterprise Information Management, 17 (3), 191-207.

Choy, K.L., Lee, W.B., \& Lo, V. (2005). A knowledge-based supplier intelligence retrieval system for outsource manufacturing. Knowledge-Based Systems, 18 (1), 1-17.

Cheraghi, S.H., Dadashzadeh, M., \& Subramanian, M (2011). Critical success factors for supplier selection: An update. Journal of Applied Business Research, 20(2), 91-108.

Degraeve Z., Labro E., \& Roodhooft F. (1991). An evaluation of vendor selection models from a total cost of ownership perspective. European Journal of Operational Research, 125 (1), 34-58.

Ding, H., Benyoucef, L., \& Xie, X. (2005). A simulation optimization methodology for supplier selection problem. International Journal Computer Integrated Manufacturing, 18 (2-3), 210-224.

Forker, L.B., \& Mendez, D. (2001). An analytical method for benchmarking best peer suppliers. International Journal of Operations and Production Management, 21(1-2), 195-209.

Florez-Lopez, R. (2007). Strategic supplier selection in the added-value perspective: A CI approach. Information Sciences, 177 (5), 1169-1179.

Garfamy, R.M. (2006). A data envelopment analysis approach based on total cost of ownership for supplier selection. Journal of Enterprise Information Management, 19 (6), 662-678.

Ghodsypour, S.H., \& O'Brien, C. (2001). The total cost of logistics in supplier selection, under conditions of multiple sourcing, multiple criteria and capacity constraint. International Journal of Production Economics, 73 (1), 15-27.

Gencer, C., \& Gürpinar, D. (2007). Analytic network process in supplier selection: A case study in an electronic firm. Applied Mathematical Modeling, 31 (11), 2475-2486.

Ho, W., Xu, X, \& Dey,P.K. (2010). Multi-criteria decision making approaches for supplier evaluation and selection: A literature review. European Journal of Operational Research, 202, 16-24.

Holt G.D. (1998). Which Contractor Selection Methodology? International Journal of Project Management, 16(3), 153-164.

Hong, G.H., Park, S.C., Jang, D.S., \& Rho, H.M. (2005). An effective supplier selection method for constructing a competitive supply-relationship. Expert Systems with Applications, 28 (4), 629-639.

Hou, J., \& Su, D. (2007). EJB-MVC oriented supplier selection system for mass customization. Journal of Manufacturing Technology Management, 18 (1), 54-71.

Huang, S.H., \& Keska, H. (2007). Comprehensive and configurable metrics for supplier selection. International Journal of Production Economics, 105 (2), 510-523.

Jiang W., \& Chan F.T.S. (2011). A new fuzzy dempster MCDM method and its application in supplier selection. Expert Systems with Applications, 38(8), 9854-9861.

Kao, C. (2010). Ranking Alternatives in Multiple Criteria Decision Analysis Based on a Common-Weight DEA. Proc. International Conference on Industrial Engineering and Operations Management Dhaka, Bangladesh.

Karpak, B., Kumcu, E., \& Kasuganti, R.R. (2001). Purchasing materials in the supply chain: Managing a multi-objective task. European Journal of Purchasing and Supply Management, 7 (3), 209-216.

Kumar J., \& Roy N. (2011). Analytic hierarchy process (AHP) for a power transmission industry to vendor selection decisions. International Journal of Computer Applications. 12(11), 26-30.

Liu, J., Ding, F.Y., \& Lall, V. (2000). Using data envelopment analysis to compare suppliers for supplier selection and performance improvement. Supply Chain Management: An International Journal, 5 (3), 143-150. 
Liu, F.H.F., \& Hai, H.L. (2005). The voting analytic hierarchy process method for selecting supplier. International Journal of Production Economics, 97 (3), 308-317.

Mondal, S., \& Chakraborty, S. (2010). Flexible Manufacturing System Selection using Data Envelopment Analysis. Proc. International Conference on Advances in Mechanical Engineering, S.V. National Institute of Technology, Surat, 852-856.

Muralidharan, C., Anantharaman, N., \& Deshmukh, S.G. (2002). A multi-criteria group decision-making model for supplier rating. Journal of Supply Chain Management, 38 (4), 22-33.

Narasimhan, R., Talluri, S., \& Mendez, D. (2001). Supplier evaluation and rationalization via data envelopment analysis: An empirical examination. Journal of Supply Chain Management, 37 (3), 28-37.

Narasimhan, R., Talluri, S., \& Mahapatra, S.K. (2006). Multiproduct, multi-criteria model for supplier selection with product life-cycle considerations. Decision Sciences, 37 (4), 577-603.

Ng, W.L. (2008). An efficient and simple model for multiple criteria supplier selection problem. European Journal of Operational Research, 186 (3), 1059-1067.

Rajan, A.J., Ganesh, K., \& Narayanan, K.V. (2010). Application of Integer Linear Programming Model for Vendor Selection in a Two Stage Supply Chain. Proc. International Conference on Industrial Engineering and Operations Management Dhaka, Bangladesh.

Ross, A., Buffa, F.P., Dröge, C., \& Carrington, D. (2006). Supplier evaluation in a dyadic relationship: An action research approach. Journal of Business Logistics, 27 (2), 75-102.

Saen, R.F. (2006). A decision model for selecting technology suppliers in the presence of nondiscretionary factors. Applied Mathematics and Computation, 181 (2), 1609-1615.

Sarkis, J., \& Talluri, S. (2002). A model for strategic supplier selection. Journal of Supply Chain Management, 38 (1), 18-28.

Sarkar, A., \& Mohapatra, P.K.J. (2006). Evaluation of supplier capability and performance: A method for supply base reduction. Journal of Purchasing and Supply Management, 12 (3), 148-163.

Seydel, J. (2006). Data envelopment analysis for decision support. Industrial Management and Data Systems, $106(1), 81-95$.

Songhori, M.J., Tavana, M., Azadeh, A., \& Khakbaz, M.H. (2011). A supplier selection and order allocation model with multiple transportation alternatives. International Journal of Advanced Manufacturing Technology, 52(1-4), 365-376.

Talluri, S. (2002). A buyer-seller game model for selection and negotiation of purchasing bids. European Journal of Operational Research, 143 (1), 171-180.

Talluri, S., \& Narasimhan, R. (2003). Vendor evaluation with performance variability: A max-min approach. European Journal of Operational Research, 146 (3), 543-552.

Talluri, S., \& Narasimhan, R. (2005). A note on "a methodology for supply base optimization". IEEE Transactions on Engineering Management, 52 (1), 130-139.

Talluri, S., Narasimhan, R., \& Nair, A. (2006). Vendor performance with supply risk: A chance-constrained DEA approach. International Journal of Production Economics, 100 (2), 212-222.

Tahriri, F., Osman, M.R., Ali, A., \& Yusuff, R.M. (2008). A review of supplier selection methods in manufacturing industries. Suranaree Journal of Science and Technology, 15(3), 201-208.

Talluri, S., \& Baker, R.C. (2002). A multi-phase mathematical programming approach for effective supply chain design. European Journal of Operational Research, 41 (3), 544-558.

Talluri, S., \& Sarkis, J. (2002). A model for performance monitoring of suppliers. International Journal of Production Research, 40 (16), 4257-4269.

Talluri, S., \& Narasimhan, R. (2004). A methodology for strategic sourcing. European Journal of Operational Research, 154 (1), 236-250.

Wadhwa, V., \& Ravindran, A.R. (2007). Vendor selection in outsourcing. Computers and Operations Research, 34 (12), 3725-3737.

Weber, C.A., Current, J.R., \& Benton, W.C. (1991). Vendor selection criteria and methods. European Journal of Operational Research, 50 (1), 2-18.

Weber, C.A. (1996). A data envelopment analysis approach to measuring vendor performance. Supply Chain Management: An International Journal, 1(1), 28-30.

Wu, T., Shunk, D., Blackhurst, J., \& Appalla, R. (2007). AIDEA: A methodology for supplier evaluation and selection in a supplier-based manufacturing environment. International Journal of Manufacturing Technology and Management, 11 (2), 174-192.

Zolghadri M., Eckert C., Zouggar S., \& Girard P. (2011). Power-based Supplier Selection in product development projects. Computers in Industry, 62(5), 487-500. 